\title{
Controlled Monofunctionalization of Molecular Spherical Nucleic Acids on a Buckminster Fullerene Core
}

\section{Gulumkar, Vijay}

2021-06-16

Gulumkar , V , Äärelä , A, Moisio , O , Rahkila , J , Tähtinen , V , Leimu , L, Korsoff , N , Korhonen, H , Poijärvi-Virta , P , Mikkola , S , Nesati , V , Vuorimaa-Laukkanen , E , Viitala , T , Yliperttula , M , Roivainen , A \& Virta , P 2021 , ' Controlled Monofunctionalization of Molecular Spherical Nucleic Acids on a Buckminster Fullerene Core ' , Bioconjugate Chemistry , vol. 32 , no. 6 , pp. 1130-1138 . https://doi.org/10.1021/acs.bioconjchem.1c00187

http://hdl.handle.net/10138/332748

https://doi.org/10.1021/acs.bioconjchem.1c00187

cc_by

publishedVersion

Downloaded from Helda, University of Helsinki institutional repository.

This is an electronic reprint of the original article.

This reprint may differ from the original in pagination and typographic detail.

Please cite the original version. 


\title{
Controlled Monofunctionalization of Molecular Spherical Nucleic Acids on a Buckminster Fullerene Core
}

\author{
Vijay Gulumkar, Antti Äärelä, ${ }^{\ddagger}$ Olli Moisio, Jani Rahkila, Ville Tähtinen, Laura Leimu, Niko Korsoff, \\ Heidi Korhonen, Päivi Poijärvi-Virta, Satu Mikkola, Victor Nesati, Elina Vuorimaa-Laukkanen, \\ Tapani Viitala, Marjo Yliperttula, Anne Roivainen, and Pasi Virta*
}

Cite This: Bioconjugate Chem. 2021, 32, 1130-1138

Read Online

ACCESS | 네 Metrics \& More | 回 Article Recommendations | sl Supporting Information

ABSTRACT: An azide-functionalized 12-armed Buckminster fullerene has been monosubstituted in organic media with a substoichiometric amount of cyclooctyne-modified oligonucleotides. Exposing the intermediate products then to the same reaction (i.e., strain-promoted alkyne-azide cycloaddition, SPAAC) with an excess of slightly different oligonucleotide constituents in an aqueous medium yields molecularly defined monofunctionalized spherical nucleic acids (SNAs). This proce-

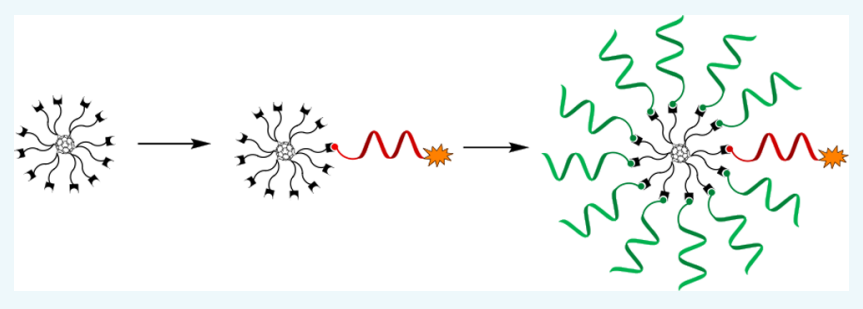
dure offers a controlled synthesis scheme in which one oligonucleotide arm can be functionalized with labels or other conjugate groups (1,4,7,10-tetraazacyclododecane-1,4,7,10-tetraacetic acid, DOTA, and Alexa-488 demonstrated), whereas the rest of the 11 arms can be left unmodified or modified by other conjugate groups in order to decorate the SNAs' outer sphere. Extra attention has been paid to the homogeneity and authenticity of the $\mathrm{C}_{60}$-azide scaffold used for the assembly of full-armed SNAs.

\section{INTRODUCTION}

Spherical nucleic acids (SNAs, introduced originally by the Chad Mirkin laboratory) consist of an appropriate core (gold, silica, liposomes, proteins) and densely packed oligonucleotide (ON) chains. ${ }^{1-7}$ They share many beneficial properties that overcome some of the major shortcomings perceived for therapeutic ONs: they have efficient free cellular uptake via class A scavenger receptor-mediated endocytosis (which correlates with the density and chemistry of the component ONs), ${ }^{8,9}$ they have muted innate immune responses and resistance to nuclease degradation (due to steric reasons), and they are large enough to avoid renal clearance. The cellular uptake occurs via an endosomal pathway, ${ }^{8-10}$ and SNAs are able to silence target RNAs via steric blocking, once they enter into the cytoplasm. ${ }^{11}$ Also, small interfering RNAs (siRNAs) can work in spherical formulation. Dicer is able to cleave siRNAs from SNAs and release them for the canonical RNA interference pathway. ${ }^{12}$ Most of the reported SNAs are polydisperse structures. The polydispersity may be a shortcoming as the data shows a similar behavior, but still a population of particles lacking thorough characterization of the molecules exists, something that is readily accessible for covalent ON conjugates. Recently, a molecular SNA, based on a Buckminster $\mathrm{C}_{60}$-fullerene core, has been described. ${ }^{13}$ This structure, consisting of antisense $\mathrm{ON}$ sequences on the $\mathrm{C}_{60}$ core, was dense enough to induce scavenger receptor-mediated endocytosis. The internalization of these particles to breast cancer (MCF7) cells was determined to be ca. 500-fold compared to the free component ONs. Regulation of protein expression by an antisense ON that targeted human epidermal growth factor receptor 2 (HER2) mRNA transcripts was also demonstrated.

Our interest in molecularly defined SNAs is to apply them as delivery vehicles together with the covalent conjugation strategy. The rationale of this idea is that radial formulation could be a simple option to emphasize the ligand-specific effect on the outer sphere of the SNAs and at the same time hide the unfavorable distribution properties of negatively charged ONs. ${ }^{14-17}$ For the monitoring of cellular uptake and biodistribution of these decorated SNAs, appropriate labeling is needed, which may cause a misleading distribution and cellular delivery of the actual structure (if all arms are labeled). Therefore, to keep the label effect minimal, an established method that allows controlled monofunctionalization of the SNAs is valuable. Furthermore, the controlled monofunctionalization can be utilized to integrate SNAs specifically with other delivery vehicles. In the present study, an azidefunctionalized 12-armed Buckminster fullerene (1) is exposed to a substoichiometric amount of cyclooctyne-modified and -labeled (DOTA and Alexa 488) ONs, which gave the monofunctionalized fullerene in relatively high yields. The

Received: April 13, 2021

Revised: $\quad$ May 7, 2021

Published: May 16, 2021 
Scheme 1. ${ }^{1} \mathrm{H}$ NMR (500 MHz, $\left.\mathrm{CDCl}_{3}\right)$ Spectrum of 1 (A) and $2(\mathrm{~B})^{a}$

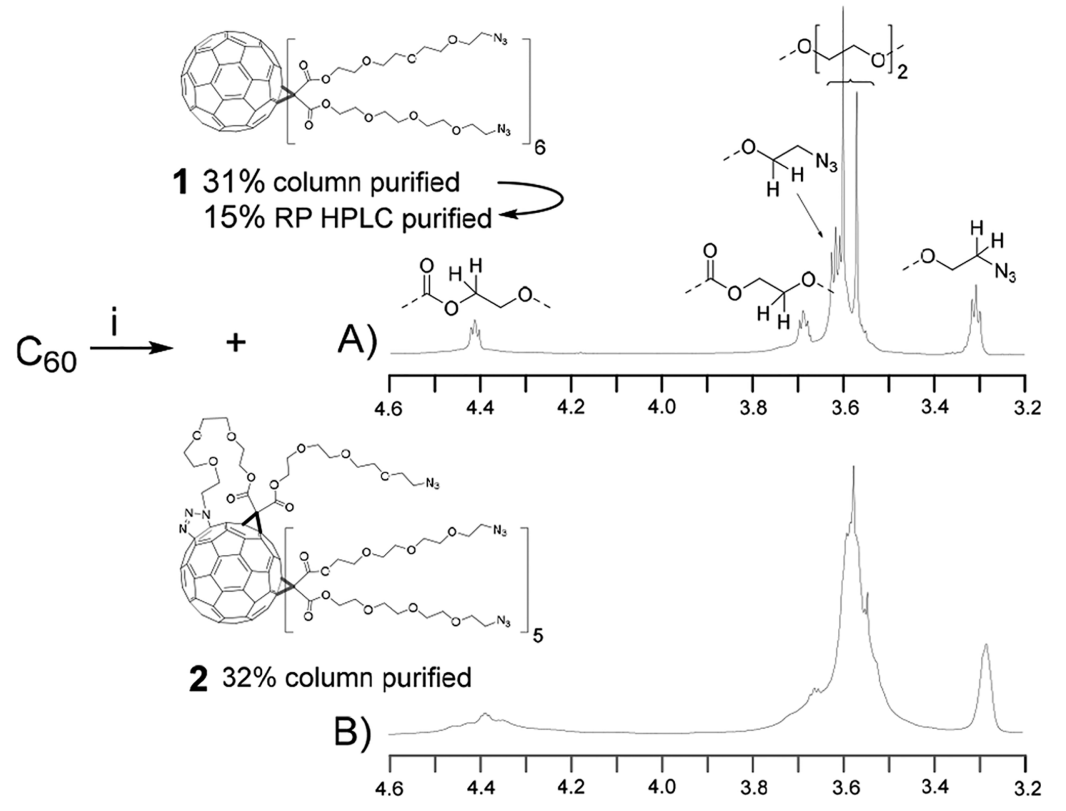

${ }^{a}$ Conditions: (i) bis(2-(2-(2-(2-azidoethoxy)ethoxy)ethoxy)ethyl)malonate, $\mathrm{CBr}_{4}, 1,8$-diazabicyclo[5,4,0]undec-7-ene (DBU), o-dichlorobenzene under argon, 3 days at room temperature.

isolated intermediate products were then exposed to an excess of slightly different ON constituents in an aqueous medium, which gave the monolabeled full-armed SNAs. This two-step process was noticed to be crucial, not only for the controlled assembly but also for the preparation of the $\mathrm{C}_{60}$-based SNAs in more general, as the solubility properties of the lipophilic $\mathrm{C}_{60}$ core and hydrophilic ONs severely retard the full decoration in one reaction medium only. Reverse-phase high-performance liquid chromatography (RP-HPLC), native polyacrylamide gel electrophoresis (PAGE), capillary electrophoresis (CE), MS spectroscopy, dynamic light scattering (DLS), and size exclusion chromatography equipped with a multiple-angle light-scattering detector (SEC-MALS) were used to analyze the end products. We also paid extra attention to the homogeneity and authenticity of the initial $\mathrm{C}_{60}$-azide scaffold (1) as it is readily contaminated by a hardly distinguishable azide- $\mathrm{C}_{60}[3+2]$ cycloaddition side product that would hamper the assembly, purification, and identification of the target SNAs. Overall, this procedure allows a controlled synthesis scheme in which one of the ON arms of SNAs can be selectively functionalized with labels or other conjugate groups. In one case, D-galactose-conjugated ONs were used to decorate the outer sphere. In addition, radiolabeling of a DOTA-labeled SNA has been demonstrated.

\section{RESULTS AND DISCUSSION}

Synthesis and Purification of the $C_{60}$-Azide Core (1). The $\mathrm{C}_{60}$-azide scaffold (1) was synthesized following a previously published procedure (Scheme 1). ${ }^{13}$ However, in our hands, Bingel's cyclopropanation ${ }^{18,19}$ between Buckminster fullerene $\left(\mathrm{C}_{60}\right)$ and bis(2-(2-(2-(2-azidoethoxy)ethoxy)ethoxy)ethyl)malonate gave a mixture of compounds (1 and $\mathbf{2}$, ca. $1: 1, \mathrm{n} / \mathrm{n}$ ) with equal molecular masses and similar NMR data ( 2 with markedly broader resonances, A vs B in Scheme 1). Repeated column chromatography and RP-HPLC purification were needed to obtain the homogenized 1 in
$15 \%$ overall isolated yield, which was used for the preparation of SNAs. In order to provide further understanding of the products' identity and applicability for the SNAs' assembly, preliminary SPAAC trials were carried out: Both $\mathbf{1}$ and $\mathbf{2}$ were exposed to an excess of bicyclo[6.1.0]non-4-yn-9-ylmethanoland 5'-2-(bicyclo[6.1.0]non-4-yn-9-yl)ethylphosphate (BCN)modified $\mathrm{T}_{6}$ sequence (ON1, following the two-step process in Scheme 2). MS (ESI-TOF) analysis verified that all 12 arms of 1 could be readily functionalized, but reactions with 2 stacked to undecafunctionalized products (Figures S6 and S7). ${ }^{1} \mathrm{H}-{ }^{15} \mathrm{~N}$ heteronuclear multiple bond correlation (HMBC) analysis was used to further verify the authenticity of 2 , which revealed that part of the nitrogen signals was characteristic to triazol and not entirely to alkylazide (Figures S8 and S9). The fact that the $[3+2]$ cycloaddition occurred upon Bingel's cyclopropanation is understandable, as this reaction has been used to functionalize the $\mathrm{C}_{60}$ core in very similar conditions. $^{20-24}$ For further evidence, ad hoc-synthesized triazolino fullerenes were synthesized by treating $\mathrm{C}_{60}$ with 2 (2-(2-(2-azidoethoxy)ethoxy)ethoxy)ethanol. The NMR signals of the triazolino fullerenes (di-, tri-, and tetrafunctionalized products obtained, Scheme S1) were comparable to trace signals of 2 .

Synthesis of Oligonucleotides. For the assembly of SNAs (S1-S6), BCN-modified ONs (ON1-ON3, ON5, and ON7-ON10, Scheme 2) were synthesized using an automated DNA/RNA synthesizer. A standard phosphoramidite coupling cycle and commercially available 2 -O-methylribonucleotide and 2 -deoxyribonucleotide building blocks were used for the assembly. 3-Phenyl 1,2,4-dithiazoline-5-one (POS) was used as a sulfurization reagent for the synthesis of ON5. Our previously reported customized solid supports ${ }^{25,26}$ were utilized for the synthesis of appropriately $3^{\prime}$-modified ONs: ON7 and ON10 with a 1,4,7,10-tetraazacyclododecane1,4,7,10-tetraacetic acid (DOTA) and a D-galactose moiety, respectively. While ON1 and ON2 are short sequences, 
Scheme $2^{a}$

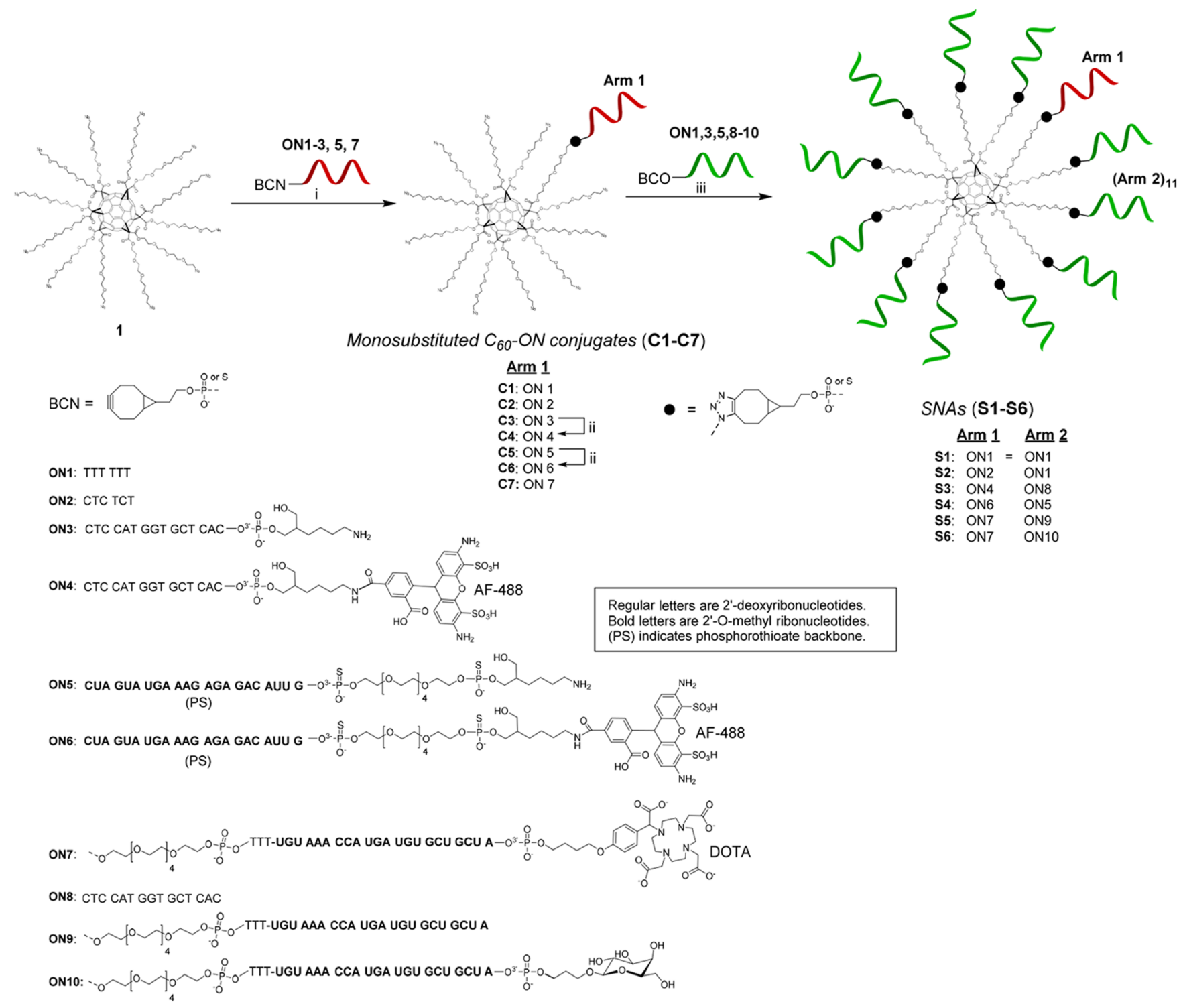

${ }^{a}$ Conditions: (i) BCN-modified oligonucleotide 1 (5 equiv) in DMSO, overnight at $25^{\circ} \mathrm{C}$, (ii) AF-488 NHS ester, $0.1 \mathrm{M}$ sodium borate (pH 8.5 ), overnight at $25{ }^{\circ} \mathrm{C}$, (iii) $\mathrm{C} 1-\mathrm{C} 7, \mathrm{BCN}$-modified oligonucleotide (1.2 equiv/arm) in aqueous $1.5 \mathrm{M} \mathrm{NaCl}, 3$ days at $25^{\circ} \mathrm{C}$.

preliminarily used to demonstrate the SNA's assembly (S1 and S2), ON3-ON10 are biologically active sequences. ON3 (and ON4) is an antisense sequence that targets HER2 mRNA transcripts. Its biological activity in SNA formulation has previously been demonstrated. ${ }^{13}$ The phosphorothioate (PS) sequence of ON5 (and ON6) is a splice switching ON that prevents expression of an androgenic receptor variant (AR-V7) in prostate cancer cells. ${ }^{27}$ The $2^{\prime}$-O-methylated sequence found in ON7, ON9, and ON10 is complementary to microRNA $15 \mathrm{~b}$ that is involved in hepatocyte apoptosis. ${ }^{28,29} \mathrm{We}$ have previously ${ }^{68} \mathrm{Ga}$ labeled this same $\mathrm{ON}$ and its glycoconjugates and studied their biodistribution by in vivo positron emission tomography/computed tomography (PET/ CT) imaging. ${ }^{30-32}$

Controlled Assembly of Monofunctionalized SNAs on the $\mathrm{C}_{60}$-Azide Core. In initial trials, the $\mathrm{C}_{60}$-azide core $\mathbf{1}$ was dissolved in a minimum volume of DMSO and treated with an excess ( $>12$ equiv) of BCN-modified oligonucleotides in an aqueous solution containing $1.5 \mathrm{M} \mathrm{NaCl}^{13}$ However, the drastically different solubility properties between the lipophilic $\mathrm{C}_{60}$-azide core (1) and the hydrophilic ONs retarded the SPAAC conjugation, and complex mixtures of products were obtained (reactions using different DMSO $-\mathrm{H}_{2} \mathrm{O}$ ratios, different spacers between the ONs and the core, BCN- vs dibenzocyclooctyne-modified ONs, and different temperature were attempted). This guided us to try a two-step process in which 1 was first conjugated with ONs in DMSO, and once the partially functionalized more hydrophilic intermediate products were obtained, the reaction was changed to an aqueous medium to yield full-armed SNAs. Interestingly, monofunctionalization proceeded in DMSO (Figure 1A, Scheme S2) with a reasonable excess of $\mathbf{1}$, which could be utilized for the controlled assembly of heteroantennary SNAs (S1--S6, Scheme 2). In optimized conditions (Scheme 2), BCN-modified ONs (ON1-3, ON5, and ON7) were treated with 5 equiv of 1 in DMSO to yield monofunctionalized $\mathrm{C}_{60}-$ 
A)

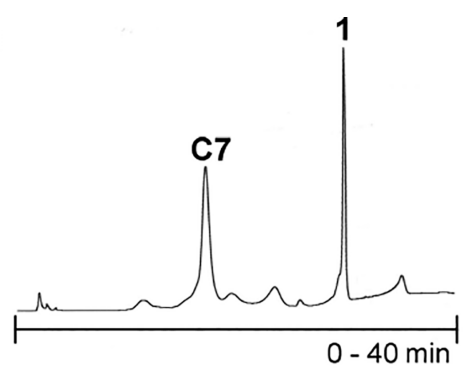

B) MS-ESI (C7)

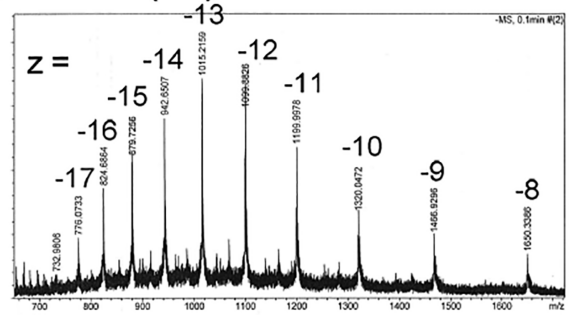

C)

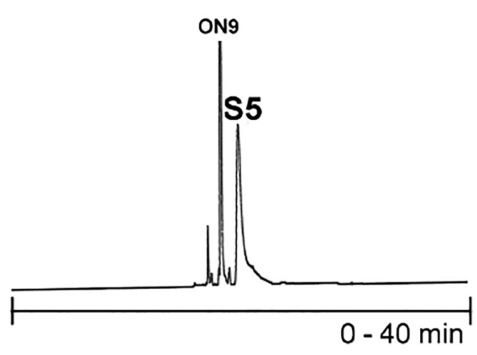

D)

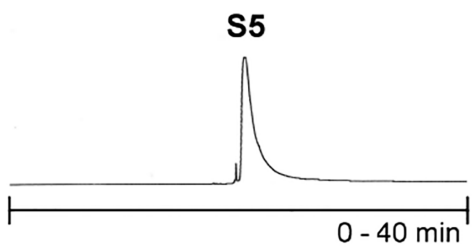

Figure 1. (A and C) Examples of RP-HPLC profiles of crude product (C7 and S5) mixtures. (B) Example of the MS-ESI spectrum of purified monosubstituted $\mathrm{C}_{60}$-ON-conjugate (C7). (D) Example of the RP-HPLC profile of purified SNA (S5).
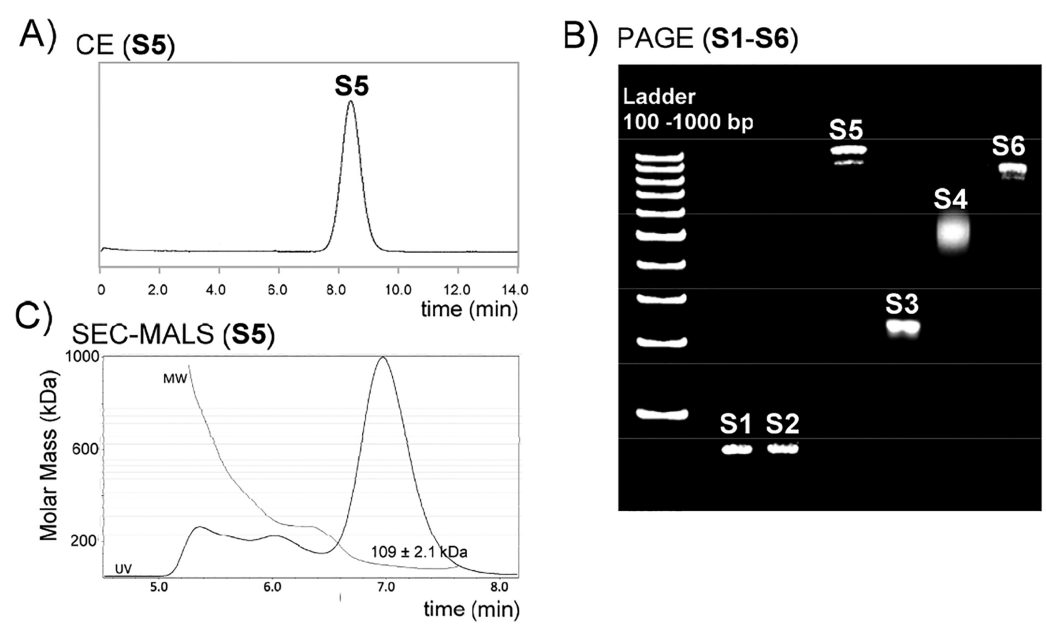

Figure 2. (A) Example of capillary electrophoregrams (CE) of purified SNA (S5). (B) Polyacrylamide gel electrophoregrams (PAGE) of purified SNAs (S1-S6). (C) Example of the SEC-MALS profile of purified SNA (S5) used to evaluate the molecular mass. For the conditions, see Experimental Section.

ON conjugates $(\mathbf{C 1}-\mathbf{C} 3, \mathbf{C 5}$, and $\mathbf{C} 7)$ in relatively high $\mathrm{RP}$ HPLC-isolated yields (45-50\%). The remaining excess of 1 could be reisolated (cf. Figure 1A) and reused. The aminomodified conjugates (C3 and C5) were labeled with Alexa488-N-hydroxysuccinimide (NHS) ester, and the conjugates (C1, C2, C4, C6, and C7) were then dissolved in aqueous 1.5 $\mathrm{M} \mathrm{NaCl}$ solution and mixed with a slight excess (12 equiv) of BCN-ONs (ON1, ON5, and ON8-ON10). ${ }^{33-35}$ After incubation for 2 days at room temperature, one additional equivalent of $\mathrm{BCN}-\mathrm{ONs}$ was added to confirm the completion of the full decoration (in overall 1.2 equiv/arm). The reaction mixtures were then incubated one more day (3 days total) and subjected as such to RP-HPLC (Figure 1C, Scheme S2). The obtained SNAs (S1-S6) were isolated in $40-57 \%$ yield according to UV absorbance at $260 \mathrm{~nm}$ (S1, S2, S5, and S6) and $488 \mathrm{~nm}$ (S3 and S4).

Characterization of the SNAs. The homogeneity and identity of the RP-HPLC-isolated SNAs were evaluated by PAGE, CE, SEC-MALS, and MS-ESI spectroscopy. As seen on
PAGE (Figure 2B), each SNA resulted in a distinct and relatively sharp band. The stereoisomeric phosphorothioate backbone of S4 caused a blurred band compared to other SNAs. On the electrophoregrams of larger SNAs (S5 and S6), faster eluting trace products ( $<5 \%$ of the total intensity) could be additionally observed that indicated incomplete decoration. Fractionation by RP-HPLC (Figure 1C) did not affect the results on PAGE, neither did the prolonged reaction time nor a higher excess of BCN-ONs (ON9 and ON10) used for the SPAAC conjugation. Despite these traces of side products (most likely 11-armed SNAs), the overall purity of the assembled SNAs after single RP-HPLC purification proved relatively high on PAGE. Next, the applicability of CE to evaluate the homogeneity of the SNAs was demonstrated (Figure 2A and Scheme S2). CE could not discriminate traces of incomplete (11-armed) products from the full-armed SNAs, but it proved to be a valuable tool to confirm the absence of smaller component ONs. SEC-MALS is a common technique employed to estimate the homogeneity, aggregation tendency, 
and molecular weight of biomolecules. ${ }^{36}$ This is particularly useful for large molecular weight compounds $(>100 \mathrm{kDa})$, characterization of which is often hardly accessible by MS spectroscopy. This was the case also with SNAs. Acceptable $m$ / $z$ data (a spectrometer equipped with a hybrid quadrupole orbitrap and nano ESI ionization was used) could be obtained for small model SNAs S1 and S2 (Figure S12), whereas humps of overlapping multiply charged ion patterns, unsuitable for reliable MS characterization, were obtained for S3-S6. In fact, even $\mathbf{S 1}$ and $\mathbf{S 2}$ were prone to form stable multiple sodium adducts (Figure S12), and the observed molecular masses were 0.1 and $0.2 \mathrm{kDa}$ higher compared to the calculated values (Table 1, entries 1 and 2). Therefore, we applied SEC-MALS

\section{Table 1. Molecular Masses of SNAs S1-S6}

$\begin{array}{cccc}\text { SNA } & \begin{array}{c}\text { calculated molecular } \\ \text { mass }(\mathrm{kDa})\end{array} & \begin{array}{c}\text { observed molecular } \\ \text { mass }(\mathrm{kDa})\end{array} & \begin{array}{c}\text { hydrodynamic } \\ \text { size }(\mathrm{nm})\end{array} \\ \text { S1 } & 27.6 & 27.8^{a} & 9.2 \pm 1.2 \\ \text { S2 } & 27.6 & 27.7^{a} & 9.6 \pm 2.5 \\ \text { S3 } & 61.2 & 62.6 \pm 0.4^{b} & 11.8 \pm 0.6 \\ \text { S4 } & 107.3 & 106.8 \pm 3.6^{b} & 16.2 \pm 0.1 \\ \text { S5 } & 109.9 & 109.3 \pm 2.1^{b} & 19.0 \pm 2.0 \\ \text { S6 } & 113.2 & 107.4 \pm 2.3^{b} & 21.4 \pm 0.8\end{array}$

${ }^{a}$ A hybrid quadrupole-orbitrap spectrometer with nano ESI-ionization was used for mass analysis (cf. Figure S12). ${ }^{b}$ The values were obtained by SEC-MALS-based estimation of the molecular mass (cf. Figure 2C).

to estimate the molecular weights of S3-S5. The samples of S3-S5 were eluted with $150 \mathrm{mM}$ phosphate buffer ( $\mathrm{pH} \mathrm{7)}$ through a $300 \AA, 2.7 \mu \mathrm{m}, 4.6 \times 300 \mathrm{~mm}$ SEC column. As seen in Figure 2C and Figure S12, each SNA resulted in a major peak (retention time ca. $7 \mathrm{~min}$ ) that represented the $70-80 \%$ mass fraction of the sample. The MALS-based estimation of the molecular weights extracted from the major peaks matched relatively well with the expected calculated values (Table 1 , entries 3-6). It may be worth mentioning that the errors of the observed molecular masses were less than the molecular mass of the component ONs. In each case, faster eluting fractions (retention time ca. 5.0-6.5 $\mathrm{min}$ ) were observed also, the molecular weight of which $(>200 \mathrm{kDa})$ may be attributed to aggregation of the SNAs (Figure 2C and Figure S12). Together with the molecular masses obtained for small model SNAs S1 and S2 and the SEC-MALS-based characterization of SNAs S3-S6, the authenticity of the products could be verified. Finally, the hydrodynamic diameter of the SNAs was determined by DLS. The diameters (ranging from 9.2 to $21.4 \mathrm{~nm}$, Table 1) of S1-S6 correlated with the lengths of the component ONs.

Melting Analysis $\left(T_{\mathrm{m}}\right)$ and Titration of SNA with a Complementary RNA Strand. In order to evaluate the hybridization properties of the $\mathrm{C}_{60}$-based SNAs, UV-melting profile experiments $\left(T_{\mathrm{m}}\right)$ and titration of $\mathbf{S} 4$ with a short model sequence of AR-V7 pre-mRNA were carried out. The S4RNA duplex resulted in a $-3{ }^{\circ} \mathrm{C}$ decrease in the $T_{\mathrm{m}}$ value when compared to the corresponding free duplex (Figure 3A). Furthermore, gentler melting profiles were observed, which was more obvious, when fully hybridized $\mathbf{S} 4$ was compared to a partially hybridized one ( 12 vs 6 equiv of complementary strands). This indicates electrostatic repulsion/steric crowding between the duplexes on fully loaded SNA ( $\mathbf{S} 4+12$ equiv of RNA). This observation is consistent with the previous findings in which a retarded loading of siRNAs onto SNAs has been observed. ${ }^{12,37-39}$ However, it is notable that the fully loaded SNA ( $44+12$ equiv of RNA) was virtually stable below the physiological temperature and the observed "premature" partial denaturation occurred at a higher temperature. Titration of S4 with the same complementary RNA verified the correct stoichiometry of the melting profiles (Figure 3B; note, the concentration of $\mathbf{S} \mathbf{4}$ was determined according to the Alexa content). Gradual addition of the complementary RNA strand increased the overall absorbance with a constant slope (hypochromic effect due to the hybridization compensates for the increased absorbance), and a turning point of the slope was observed once the amount of the complementary RNA exceeded the fully occupied SNA. The observed turning point at 11.9 equivalents matched well with the correct 12armed SNA structure.

Radiolabeling. To evaluate the applicability of DOTA as a ${ }^{68} \mathrm{Ga}$-chelating agent on SNAs, S5 was used as a model in
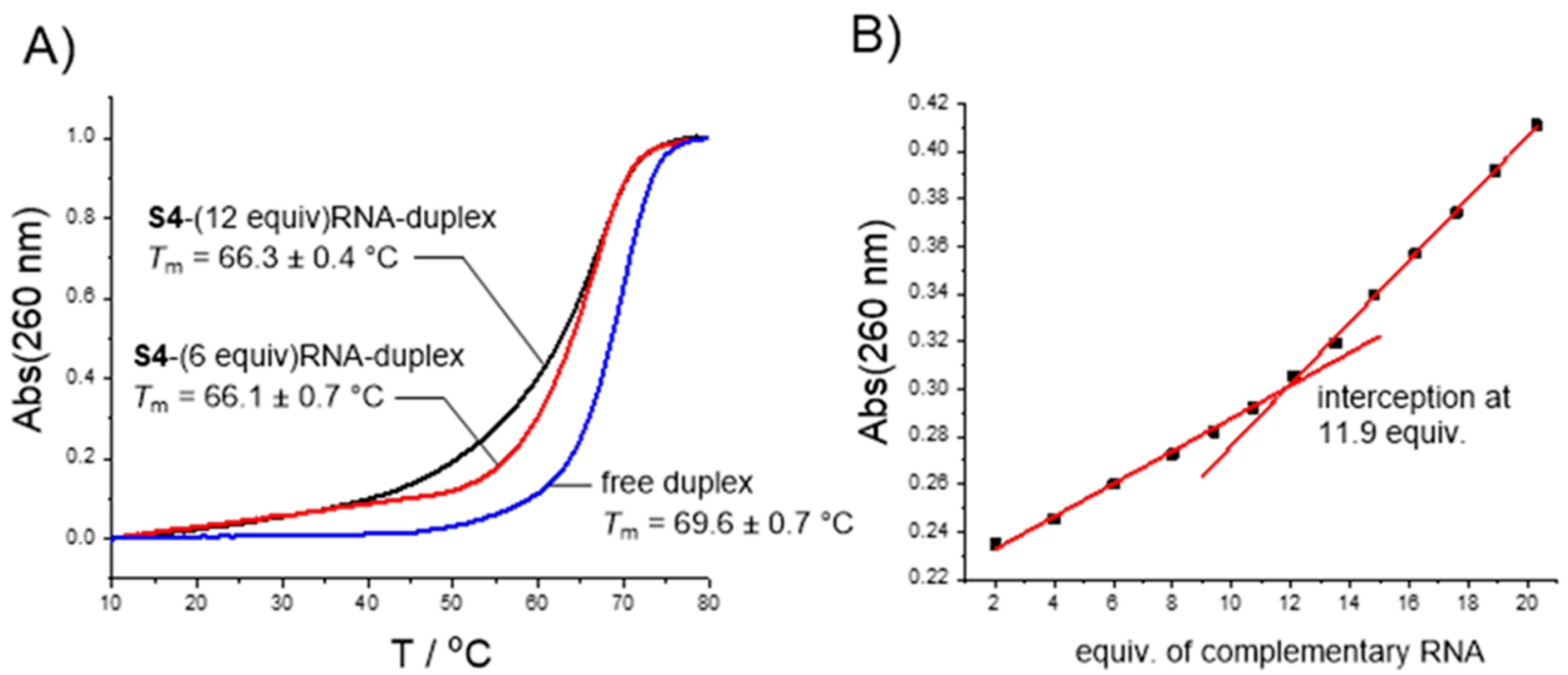

Figure 3. Melting profile analysis and titration of $\mathbf{S} 4$ with complementary RNA: C AAU GUC UCU CUU UCA UAC UAG. For the formation of free duplex CUA GUA UGA AAG AGA GAC AUU G (2'-O-methyl RNA phosphorothioate) was used. 
preliminary radiolabeling experiments. With these small-scale trials (1-2 nmol of S5) we also tried to find conditions that minimize precursor loading at the expense of yield. Radiochemical yields of up to $68 \mathrm{MBq}$ were achieved (24\% decay corrected yield). Radiochemical purity was measured at up to $69 \%$ as measured by PAGE and $73 \%$ by ultrafiltration (Figure 4). We observed that size exclusion purification of the reaction

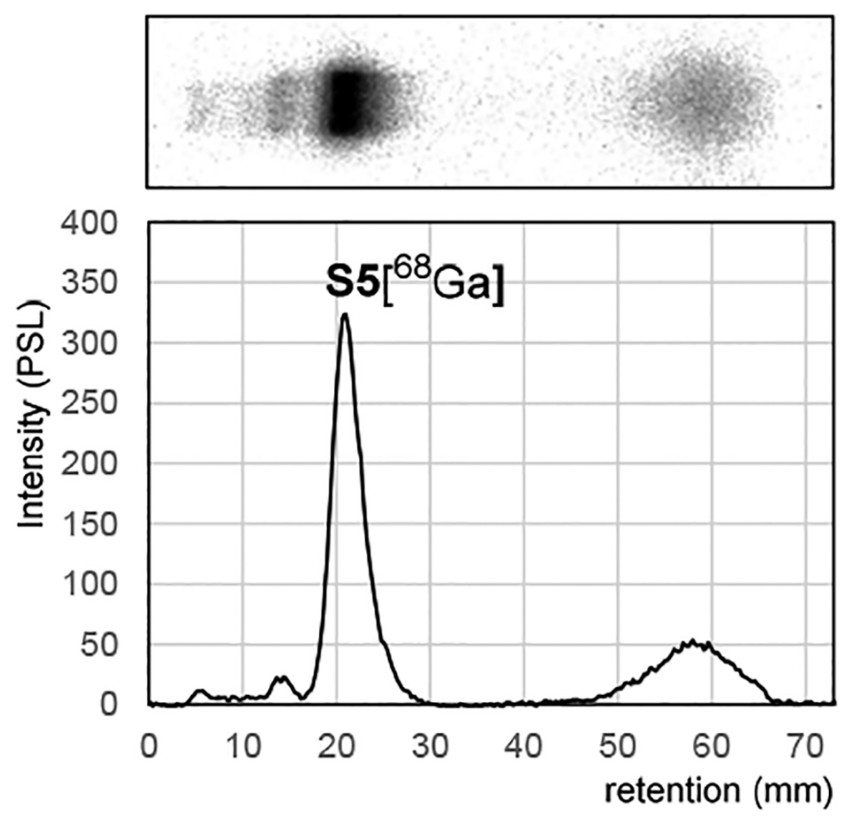

Figure 4. Representative polyacrylamide gel electrophoresis (PAGE) autoradiography image and quantification of radiolabeled SNA $\mathrm{S5}\left[{ }^{68} \mathrm{Ga}\right]$.

mixture could not sufficiently remove all unbound ${ }^{68} \mathrm{Ga}$, even when two successive column purifications were used. Also, commonly used solid-phase extraction columns with $\mathrm{C} 8, \mathrm{C} 18$, and hydrophobic lipophilic balance (HLB) solid phases were attempted. Due to the difficulty of separating unbound ${ }^{68} \mathrm{Ga}$ and the low performance of the size exclusion purification, we suspected unspecific binding of ${ }^{68} \mathrm{Ga}$ to the SNA structure. This was confirmed by incubating the end product $\left(\mathrm{S5}\left[{ }^{68} \mathbf{G a}\right]\right.$ ) in $50 \mathrm{mM}$ ethylenediaminetetraacetic acid/phosphate-buffered saline (EDTA/PBS) at $\mathrm{pH} 7.4$ in $37{ }^{\circ} \mathrm{C}$. As expected, we observed a further $10 \%$ increase in the unbound activity fraction after $1 \mathrm{~h}$ EDTA challenge, as measured by ultrafiltration. This relatively stable unspecific ${ }^{68} \mathrm{Ga}$ binding to the densely packed $\mathrm{ON}$ construct is in agreement with the behavior of the SNAs in MS in which relatively stable multiple sodium adducts were observed (Table 1 , entries 1 and 2 ). Although the small-scale (1-2 nmol of precursor S5 loading) experiments did not produce acceptable purities, valuable information was obtained, which will aid future in vivo PET/ CT imaging studies of SNAs. Due to the unspecific ${ }^{68} \mathrm{Ga}$ binding observed, an indirect labeling method, such as a click reaction with a reactive agent prelabeled with either ${ }^{68} \mathrm{Ga}$ or ${ }^{18} \mathrm{~F}$, may prove a more suitable choice for SNAs. ${ }^{40,41}$

\section{CONCLUSION}

A two-step procedure that allows controlled assembly of monofunctionalized $\mathrm{C}_{60}$-based SNAs has been described. This preliminary data opens the door for controlled decoration of SNAs with labels or tissue/organ-specific ligands and possibility integrating them specifically to other delivery vehicles. Despite the multicomponent SPAAC-based assembly and two RP-HPLC purifications, the overall yield of these SNAs proved to be relatively high, ca. $20-30 \%$. We also paid extra attention to the homogeneity of the $\mathrm{C}_{60}$-azide scaffold (1). 1 was noticed to be readily contaminated by a hardly distinguishable azide- $\mathrm{C}_{60}[3+2]$ cycloaddition side product (2) that would hamper the assembly, purification, and identification of the SNAs. The homogeneity and authenticity of the SNAs were evaluated by various methods, including RPHPLC, native PAGE, CE, SEC-MALS, and MS-ESI spectroscopy. While PAGE was a superior technique to evaluate the homogeneity of these $\mathrm{C}_{60}$-based SNAs, SEC-MALS could be used for rough evaluation of the molecular weights. Preliminary radiolabeling experiments suggested that the chelation-based techniques should be replaced by a covalent radiolabeling strategy to prevent unspecific metal ion $\left({ }^{68} \mathrm{Ga}\right)$ binding to the densely packed $\mathrm{ON}$ shell of these nanoparticles. The described procedure with detailed analytical control of each single step will expectedly promote design of new molecularly defined monofunctionalized SNAs, which may find interesting therapeutic and diagnostic applications.

\section{EXPERIMENTAL SECTION}

Synthesis and Purification of the $\mathrm{C}_{60}$-Azide Core (1). 1 was synthesized by Bingel cyclopropanation following the previously published procedure: ${ }^{13}$ Buckminster fullerene $\mathrm{C}_{60}$ (0.40 g, $0.56 \mathrm{mmol}$ ) was dissolved in dry and degassed (oxygen removed by bubbling with argon) $o$-dichlorobenzene $(140 \mathrm{~mL})$. Bis(2-(2-(2-(2-azidoethoxy)ethoxy)ethoxy)ethyl)malonate (2.8 g, $5.6 \mathrm{mmol}, 10$ equiv), $\mathrm{CBr}_{4}(19 \mathrm{~g}, 56 \mathrm{mmol}$, 100 equiv), and 1,8-diazabicyclo[5,4,0] undec-7-ene (DBU, 1.7 $\mathrm{mL}, 11 \mathrm{mmol}, 20$ equiv) were added, and the mixture was stirred 3 days at room temperature under argon. The mixture was purified by silica gel column chromatography (pore size 60 Å, 230-400 mesh particle size, 40-63 $\mu \mathrm{m}$ particle size, isocratic elution with $2 \% \mathrm{MeOH}$ in dichloromethane, twice) to yield the desired product $\mathbf{1}(0.66 \mathrm{~g}, 32 \%)$ and a near identically behaving side product $2(0.65 \mathrm{~g}, 31 \%$, for further characterization, see Figures S2-S9). A sample $(30 \mathrm{mg})$ of columnpurified 1 was further purified by RP-HPLC to yield homogenized 1 (7 mg, 23\%, overall yield $15 \%)$, which was used for the preparation of SNAs. 1: ${ }^{1} \mathrm{H}$ NMR (500 MHz, $\left.\mathrm{CDCl}_{3}\right) \delta 4.43(\mathrm{t}, 24 \mathrm{H}, J=4.1 \mathrm{~Hz}), 3.75(\mathrm{t}, 24 \mathrm{H}, J=4.1 \mathrm{~Hz})$, $3.69(\mathrm{t}, 24 \mathrm{H}, J=4.3 \mathrm{~Hz}), 3.67(\mathrm{~s}, 48 \mathrm{H}), 3.64(\mathrm{~s}, 48 \mathrm{H}), 3.40(\mathrm{t}$, $24 \mathrm{H}, J=4.2 \mathrm{~Hz}) ;{ }^{13} \mathrm{C} \mathrm{NMR}\left(125 \mathrm{MHz}, \mathrm{CDCl}_{3}\right) \delta 163.5$, 145.8, 141.0, 70.7, 70.0, 69.0, 68.6, 65.8, 50.7, 45.2; MS (ESITOF) molecular mass for $\mathrm{C}_{174} \mathrm{H}_{192} \mathrm{~N}_{36} \mathrm{O}_{60} \mathrm{Na}_{3} 3816.6$, found 3816.4 (calculated from $[(\mathrm{M}+3 \mathrm{Na}) / 3]^{3+}$.

Synthesis of $\mathrm{C}_{60}-\mathrm{ON}$ Conjugates $\mathrm{C} 1-\mathrm{C} 3, \mathrm{C} 5$, and C7. General procedure: $\mathrm{BCN}-$ modified oligonucleotide (ON1-3, ON5, or ON7, $0.1 \mu \mathrm{mol}$ in $60 \mu \mathrm{L}$ of $\mathrm{H}_{2} \mathrm{O}$ ) was slowly added to a mixture of $\mathrm{C}_{60}$ core $1(0.5 \mu \mathrm{mol}$ in $540 \mu \mathrm{L}$ of DMSO $)$ in a microcentrifuge tube. The reaction mixture was gently shaken overnight at room temperature and subjected to RP-HPLC (Figure 1A and Scheme S2). An analytical RP-HPLC column $(250 \times 4.6 \mathrm{~mm}, 5 \mu \mathrm{m})$, a gradient elution from $40 \%$ to $100 \%$ $\mathrm{MeCN}$ in $50 \mathrm{mmol} \mathrm{L}^{-1}$ triethylammonium acetate over 30 min, and detection at $260 \mathrm{~nm}$ were applied. The $\mathrm{C}_{60}-\mathrm{ON}$ conjugate $(\mathbf{C} \mathbf{1}-\mathbf{C} 7)$ and unreacted fullerene core $\mathbf{1}$ were collected individually and lyophilized to dryness. The authenticity of the products was verified by MS (ESI-TOF) (Figure 1B and Figure S11). Isolated yields (45-50\%, only 
slight differences in yields between the different conjugates observed) of $\mathbf{C 1}-\mathbf{C 7}$ were determined by UV absorbance at $260 \mathrm{~nm}$.

Synthesis of Alexa-488-Labeled Conjugates C4 and C6. AF488 NHS ester $(0.4 \mu \mathrm{mol}$ in $6 \mu \mathrm{L}$ of DMSO $)$ was added to a buffered mixture of $\mathrm{C}_{60}-\mathrm{ON}$ conjugate $(50 \mathrm{nmol}$ of $\mathrm{C} 3$ or $\mathrm{C5}$ in $60 \mu \mathrm{L}$ of $0.1 \mathrm{M}$ sodium borate, $\mathrm{pH} 8.5)$. The reaction mixture was gently shaken overnight at room temperature and subjected to RP-HPLC. An analytical RPHPLC column $(250 \times 4.6 \mathrm{~mm}, 5 \mu \mathrm{m})$, a gradient elution from $40 \%$ to $100 \% \mathrm{MeCN}$ in $50 \mathrm{mmol} \mathrm{L}^{-1}$ triethylammonium acetate over $30 \mathrm{~min}$, and detection at $260 \mathrm{~nm}$ were used. The product fractions were collected and lyophilized to dryness. The authenticity of the products ( $\mathbf{C 4}$ and $\mathbf{C 6}$ ) was verified by MS (ESI-TOF) (Figure S11). Isolated yields (C4, 32\%; C6, $62 \%$ ) of the products were determined by UV absorbance at $488 \mathrm{~nm}$.

Assembly of SNAs (S1-S6). General procedure: $\mathrm{C}_{60}-\mathrm{ON}$ conjugate $\left(\mathbf{C 1}-\mathbf{C} 7,20 \mathrm{nmol}\right.$ in $55 \mu \mathrm{L}$ of $\left.\mathrm{H}_{2} \mathrm{O}\right)$ was mixed with BCN-ON (ON1, ON3, ON5, and ON8-ON10, $240 \mathrm{nmol}$ in $145 \mu \mathrm{L}$ of $\left.\mathrm{H}_{2} \mathrm{O}\right)$, and $100 \mu \mathrm{L}$ of $4.65 \mathrm{M} \mathrm{NaCl}$ was added. The reaction mixture was gently shaken for 2 days at room temperature, and then one additional equivalent of $\mathrm{BCN}-\mathrm{ON}$ was added. The mixture was then incubated one more day (72 $\mathrm{h}$ total using 1.2 equiv of $\mathrm{BCN}-\mathrm{ON} /$ azide arm) and subjected to RP-HPLC. An analytical RP-HPLC column Phenomenex, Aeris $3.6 \mu \mathrm{m}$ WIDEPORE XB-C18 $200 \AA$, $150 \times 4.6 \mathrm{~mm}$, a linear gradient from $5 \%$ to $60 \% \mathrm{MeCN}$ in $50 \mathrm{mmol} \mathrm{L}^{-1}$ triethylammonium acetate over $40 \mathrm{~min}$, a flow rate of $1.0 \mathrm{~mL}$ $\min ^{-1}$, and detection at $260 \mathrm{~nm}$ were used for purification (Figure 1C and Scheme S2). The product (S1-S6) fractions were collected and lyophilized to dryness. Isolated yields (40$57 \%$ ) of the products were determined by UV absorbance at $260 \mathrm{~nm}$ (S1, S2, S5, and S6) and $488 \mathrm{~nm}$ (S3 and S4). The obtained SNAs were characterized by MS-ESI (equipped with a hybrid quadrupole orbitrap and nano-ESI ionization) (S1 and S2) and SEC-MALS (S3-S6) (Table 1, Figure 2C, and Figure S12). For the homogeneity and particle size evaluation of S1-S6, see the PAGE (Figure 2B), CE (Figure 2A and Scheme S2), SEC-MALS (Figure 2C, Scheme S2), and DLS experiments described below.

PAGE Analysis of SNAs. Native 6\% Tris base, boric acid, EDTA, and acrylamide (TBE) gel were used to check SNAs' purity. A precast gel cover $(10 \mathrm{~cm} \times 10 \mathrm{~cm}$ in size, Thermo Fisher Scientific) was fixed into a vertical electrophoresis chamber, and the running buffer ( $90 \mathrm{mM}$ Tris, $90 \mathrm{mM}$ borate, and $2 \mathrm{mM}$ EDTA, $8.3 \mathrm{pH}$ ) was filled into the chamber. SNA samples $(5 \mu \mathrm{L}$ of $0.1 \mu \mathrm{M}$ SNAs mixed with $5 \mu \mathrm{L}$ of TBE

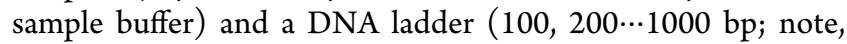
the ladder is just used to confirm the quality and comparability of the runs and cannot be used for size evaluation of the SNAs) were loaded and electrophoresed at constant $200 \mathrm{~V}(45 \mathrm{~mA})$ for approximately $30 \mathrm{~min}$. After completion of electrophoresis, gel was removed from the chamber and the SNA bands were monitored either directly by UV or after staining by SYBRTM Gold Nucleic Acid Stain (Thermo Fisher Scientific).

Capillary Electrophoresis Experiments. Samples were analyzed by capillary zone electrophoresis in a fused silica capillary of $75 \mu \mathrm{m}$ i.d. and $57 \mathrm{~cm}$ effective length. The background electrolyte was $0.3 \mathrm{M}$ citrate buffer, $\mathrm{pH}$ 3.1. A voltage of $15 \mathrm{kV}$ and pressure of 0.3 PSI were applied. UV detection at $\lambda=260 \mathrm{~nm}$ was used.
SEC-MALS Experiments. SEC-MALS was performed using an Agilent Technologies 1260 Infinity II HPLC system (sampler, pump, and UV-vis detector) equipped with a Wyatt Technologies miniDAWN light scattering detector and Wyatt Technologies Optilab refractive index detector. An Agilent AdvanceBio SEC $300 \AA 2.7 \mu \mathrm{m} 4.6 \times 300 \mathrm{~mm}$ column and 150 $\mathrm{mM}$ sodium phosphate, $\mathrm{pH} 7.0$, as mobile phase eluting at a rate of $0.2 \mathrm{~mL} \mathrm{~min}^{-1}$ and run time of $20 \mathrm{~min}$ were used for each experiment. For each run, $4 \mu \mathrm{L}$ of sample with a SNA concentration of $1 \mathrm{mg} \mathrm{mL}^{-1}$ in Milli-Q water was loaded onto the pre-equilibrated column. Detector signals were aligned with a bovine serum albumin (BSA) standard, which was analyzed prior to SNA samples. The RI and MALS signals were used for the MW calculations using an average refractive index increment $(\mathrm{d} n / \mathrm{d} c)$ of $0.1703 \mathrm{~mL} / \mathrm{g}$.

Melting Experiments $\left(T_{\mathrm{m}}\right)$ and Titration of S4 with a Complementary RNA. The melting curves (absorbance vs temperature) were measured at $260 \mathrm{~nm}$ on a UV-vis spectrometer equipped with a multiple cell holder and a Peltier temperature controller. The temperature was changed at a rate of $0.5{ }^{\circ} \mathrm{C} \mathrm{min}^{-1}$ between 10 and $80{ }^{\circ} \mathrm{C}$. The measurements were performed in $10 \mathrm{mmol} \mathrm{L}^{-1}$ sodium cacodylate ( $\mathrm{pH} 7.0$ ) with $0.1 \mathrm{~mol} \mathrm{~L}^{-1} \mathrm{NaCl}$ and $1.0 \mu \mathrm{mol}$ $\mathrm{L}^{-1}$ ON. $T_{\mathrm{m}}$ values were determined as the maximum of the first derivative of the melting curve. The UV titration of S4 (absorbance vs equivalents of complementary RNA oligonucleotide added) was performed in $10 \mathrm{mmol} \mathrm{L}^{-1}$ sodium cacodylate ( $\mathrm{pH} 7.0$ ) with $0.1 \mu \mathrm{mol} \mathrm{L}{ }^{-1} \mathrm{NaCl}$ and $63 \mathrm{nmol} \mathrm{L}^{-1}$ S4. RNA oligonucleotide with a complementary sequence to S4 was added gradually in the solution, and the total absorbance at $260 \mathrm{~nm}$ was monitored with an UV-vis spectrometer. The sequence of complementary RNA was $\mathrm{C}$ AAU GUC UCU CUU UCA UAC UAG. For the formation of free duplex, CUA GUA UGA AAG AGA GAC AUU G (2'-Omethyl RNA phosphorothioate) was used.

DLS Experiments. The size of the SNAs was measured at room temperature using a Zetasizer Nano ZS90 (Malvern Instruments Ltd., UK). The settings and conditions for the measurements were as follows: material Protein (RI, 1.450; absorption, 0.001 ), dispersant water (viscosity, 0,8872 cP; RI, 1.330) temperature was $20^{\circ} \mathrm{C}$, and equilibration time was $60 \mathrm{~s}$. Each sample $(10 \mu \mathrm{g}$ of SNA in $100 \mu \mathrm{L}$ of aqueous $10 \mathrm{mmol}$ $\mathrm{L}^{-1} \mathrm{PBS}, 2.7 \mathrm{mmol} \mathrm{L}^{-1} \mathrm{M} \mathrm{KCl}, 0.137 \mathrm{~mol} \mathrm{~L}^{-1} \mathrm{NaCl}, \mathrm{pH} 7.4$ ) was measured three times.

Radiolabeling Experiments. $\left[{ }^{68} \mathrm{Ga}\right] \mathrm{GaCl}_{3}$ was eluted from an IGG-100 ${ }^{68} \mathrm{Ge} /{ }^{68} \mathrm{Ga}$ generator with $0.1 \mathrm{M} \mathrm{HCl}$ through a Strata SCX cartridge into a waste container. The cartridge was then eluted with $300 \mu \mathrm{L}$ of $1.0 \mathrm{M}$ sodium chloride/0.1 M HCl solution, and an aliquot $(200 \mu \mathrm{L})$ was transferred to a reaction vial preloaded with a mixture of HEPES (12 mg) and S5 (1-2 nmol) in $50 \mu \mathrm{L}$ of water. Gentisic acid $(10 \mu \mathrm{L}, 0.1 \mathrm{M}$ in water) was added as a radical scavenger to counter possible radiolysis. The reaction mixture was then incubated at $70{ }^{\circ} \mathrm{C}$ for $15 \mathrm{~min}$. The mixture was cooled on ice after incubation and purified using consecutive Illustra NAP-5 and NAP-10 size-exclusion columns (Cytiva, USA) equilibrated with phosphate-buffered saline (PBS, $\mathrm{pH}$ 7.4). This afforded the end product formulation in $1.2 \mathrm{~mL}$ of phosphate-buffered saline (PBS). Radiochemical purity was determined by native PAGE and ultrafiltration. PAGE was carried out with TBE-buffered $6 \%$ polyacrylamide gels in a Biorad miniprotean II system (Bio-Rad Laboratories, Hercules, CA, USA) ran at $250 \mathrm{~V}$. The gels were developed on BAS- 
TR2025 phosphor imaging plates and analyzed with a BAS5000 scanner (Fuji, Tokyo, Japan). Ultrafiltration was done in triplicate by loading $0.5 \mathrm{~mL}, 30 \mathrm{kDa}$ Microcon filters (Millipore, Bedford, MA, USA), with $100 \mu \mathrm{L}$ of PBS and 1 $\mu \mathrm{L}$ of reaction mixture. The filters were centrifuged three times for $5 \mathrm{~min}$ at $14000 \mathrm{~g}$, with addition of $100 \mu \mathrm{L}$ of PBS between spins. The activities of the filter and the filtrate were measured with a 1480 Wizard gamma counter (PerkinElmer/Wallac, Turku, Finland), and the purity was calculated by dividing the filter activity by the total activity.

\section{ASSOCIATED CONTENT}

\section{SI Supporting Information}

The Supporting Information is available free of charge at https://pubs.acs.org/doi/10.1021/acs.bioconjchem.1c00187.

Further characterization data of $\mathbf{1}$ and 2, monosubstituted $\mathrm{C}_{60}$-conjugates $\mathrm{C1}-\mathrm{C} 7$, and SNAs (S1-S6) (PDF)

\section{AUTHOR INFORMATION}

\section{Corresponding Author}

Pasi Virta - Department of Chemistry, University of Turku, FI-20014 Turku, Finland; Department of Biologics, Orion Pharma, 20101 Turku, Finland; (1) orcid.org/0000-00026218-2212; Phone: +358 503285719; Email: pamavi@ utu.fi

\section{Authors}

Vijay Gulumkar - Department of Chemistry, University of Turku, FI-20014 Turku, Finland

Antti Ä̈relä - Department of Chemistry, University of Turku, FI-20014 Turku, Finland

Olli Moisio - Turku PET Centre, University of Turku, FI20520 Turku, Finland

Jani Rahkila - Instrument Centre, Faculty of Science and Engineering, Åbo Akademi University, FI-20500 Åbo, Finland

Ville Tähtinen - Department of Chemistry, University of Turku, FI-20014 Turku, Finland

Laura Leimu - Department of Biologics, Orion Pharma, 20101 Turku, Finland

Niko Korsoff - Department of Chemistry, University of Turku, FI-20014 Turku, Finland

Heidi Korhonen - Department of Chemistry, University of Turku, FI-20014 Turku, Finland; 이이.org/0000-00016974-9907

Päivi Poijärvi-Virta - Department of Chemistry, University of Turku, FI-20014 Turku, Finland

Satu Mikkola - Department of Chemistry, University of Turku, FI-20014 Turku, Finland

Victor Nesati - Department of Biologics, Orion Pharma, 20101 Turku, Finland

Elina Vuorimaa-Laukkanen - Faculty of Engineering and Natural Sciences, Tampere University, FI-33014 Tampere, Finland

Tapani Viitala - Division of Pharmaceutical Biosciences, Faculty of Pharmacy, University of Helsinki, FI-00014 Helsinki, Finland; (i) orcid.org/0000-0001-9074-9450

Marjo Yliperttula - Division of Pharmaceutical Biosciences, Faculty of Pharmacy, University of Helsinki, FI-00014 Helsinki, Finland
Anne Roivainen - Turku PET Centre, University of Turku, FI-20520 Turku, Finland

Complete contact information is available at:

https://pubs.acs.org/10.1021/acs.bioconjchem.1c00187

\section{Author Contributions}

${ }^{\dagger}$ V.G. and A.Ä.: These authors contributed equally.

\section{Author Contributions}

The manuscript was written through contributions of all authors. All authors have given approval to the final version of the manuscript.

Notes

The authors declare no competing financial interest.

\section{ACKNOWLEDGMENTS}

Financial support from the Academy of Finland (308931) and Business Finland (448/31/2018) is acknowledged.

\section{REFERENCES}

(1) Rosi, N. L., Giljohann, D. A., Thaxton, C. S., Lytton-Jean, A., Han, M. S., and Mirkin, C. A. (2006) Oligonucleotide-Modified Gold Nanoparticles for Intracellular Gene Regulation. Science 312, 10271030.

(2) Cutler, J. I., Auyeung, E., and Mirkin, C. A. (2012) Spherical Nucleic Acids. J. Am. Chem. Soc. 134, 1376-1391. (c) Young, K. L., Scott, A. W., Hao, L., Mirkin, S. E., Liu, G., and Mirkin, C. A. (2012) Hollow Spherical Nucleic Acids for Intracellular Gene Regulation Based Upon Biocompatible Silica Shells. Nano Lett. 12, 3867-3871.

(3) Zheng, D., Giljohann, D. A., Chen, D. L., Massich, M. D., Wang, X. Q., Iordanov, H., Mirkin, C. A., and Paller, A. S. (2012) Topical Delivery of siRNA-based Spherical Nucleic Acid Nanoparticle Conjugates for Gene Regulation. Proc. Natl. Acad. Sci. U. S. A. 109, 11975-11980.

(4) Jensen, S. A., Day, E. S., Ko, C. H., Hurley, L. A., Luciano, J. P., Kouri, F. M., Merkel, T. J., Luthi, A. J., Patel, P. C., Cutler, J. I., et al. (2013) Spherical Nucleic Acid Nanoparticle Conjugates as an RNAiBased Therapy for Glioblastoma. Sci. Transl. Med. 5, 209 ra 152.

(5) Alhasan, A. H., Patel, P. C., Choi, C. H. J., and Mirkin, C. A. (2014) Exosome Encased Spherical Nucleic Acid Gold Nanoparticle Conjugates as Potent microRNA Regulation Agents. Small 10, 186192.

(6) Randeria, P. S., Seeger, M. A., Wang, X. O., Wilson, H., Shipp, D., Mirkin, C. A., and Paller, A. S. (2015) siRNA-based Spherical Nucleic Acids Reverse Impaired Wound Healing in Diabetic Mice by Ganglioside GM3 Synthase Knockdown. Proc. Natl. Acad. Sci. U. S. A. 112 , 5573-5578.

(7) Krishnamoorthy, K., Hoffmann, K., Kewalramani, S., Brodin, J. D., Moreau, L. M., Mirkin, C. A., Olvera de la Cruz, M., and Bedzyk, M. J. (2018) Defining the Structure of a Protein-Spherical Nucleic Acid Conjugate and Its Counterionic Cloud. ACS Cent. Sci. 4, 378386.

(8) Choi, C. H. J., Hao, L., Narayan, S. P., Auyeung, E., and Mirkin, C. A. (2013) Mechanism for the Endocytosis of Spherical Nucleic Acid Nanoparticle Conjugates. Proc. Natl. Acad. Sci. U. S. A. 110, 7625-7630.

(9) Patel, P. C., Giljohann, D. A., Daniel, W. L., Zheng, D., Prigodich, A. E., and Mirkin, C. A. (2010) Scavenger Receptors Mediate Cellular Uptake of Polyvalent Oligonucleotide-Functionalized Gold Nanoparticles. Bioconjugate Chem. 21, 2250-2256.

(10) Narayan, S. P., Choi, C. H. J., Hao, L., Calabrese, C. M., Auyeung, E., Zhang, C., Goor, O. J. G. M., and Mirkin, C. A. (2015) The Sequence-Specific Cellular Uptake of Spherical Nucleic Acid Nanoparticle Conjugates. Small 11, 4173-4182.

(11) Wu, X. A., Choi, C. H. J., Zhang, C., Hao, L., and Mirkin, C. A. (2014) Intracellular Fate of Spherical Nucleic Acid Nanoparticle Conjugates. J. Am. Chem. Soc. 136, 7726-7733. 
(12) Yamankurt, G., Stawicki, R. J., Posadas, D. M., Nguyen, J. Q., Carthew, R. W., and Mirkin, C. A. (2020) The Effector Mechanism of siRNA Spherical Nucleic Acids. Proc. Natl. Acad. Sci. U. S. A. 117, 1312-1320.

(13) Li, H., Zhang, B., Lu, X., Tan, X., Jia, F., Xiao, Y., Cheng, Z., Li, Y., Silva, D. O., Schrekker, H. S., Zhang, K., Mirkin, C. A., et al. (2018) Molecular Spherical Nucleic Acids. Proc. Natl. Acad. Sci. U. S. A. $115,4340-4344$.

(14) Barnaby, S. N., Perelman, G. A., Kohlstedt, K. L., Chinen, A. B., Schatz, G. C., and Mirkin, C. A. (2016) Design Considerations for RNA Spherical Nucleic Acids (SNAs). Bioconjugate Chem. 27, 21242131.

(15) Chinen, A. B., Ferrer, J. R., Merkel, T. J., and Mirkin, C. A. (2016) Relationships between Poly(ethylene glycol) Modifications on RNA-Spherical Nucleic Acid Conjugates and Cellular Uptake and Circulation Time. Bioconjugate Chem. 27, 2715-2721.

(16) Zhang, K., Hao, H., Hurst, S. J., and Mirkin, C. A. (2012) Antibody-Linked Spherical Nucleic Acids for Cellular Targeting. J. Am. Chem. Soc. 134, 16488-16491.

(17) Chinen, A. B., Guan, C. M., Ko, C. H., and Mirkin, C. A. (2017) The Impact of Protein Corona Formation on the Macrophage Cellular Uptake and Biodistribution of Spherical Nucleic Acids. Small 13, 1603847.

(18) Bingel, C. (1993) Cyclopropanierung von Fullerenen. Chem. Ber. 126, 1957-1959.

(19) Iehl, J., Pereira de Freitas, R., Delavaux-Nicot, B., and Nierengarten, J.-F. (2008) Click chemistry for the Efficient Preparation of Functionalized [60]Fullerene Hexakis-Adducts. Chem. Commun., 2450-2452.

(20) Grosser, T., Prato, M., Lucchini, V., Hirsch, A., and Wudl, F. (1995) Ring Expansion of the Fullerene Core by Highly Regioselective Formation of Diazafulleroids. Angew. Chem., Int. Ed. Engl. 34, 1343-1345.

(21) Prato, M., Li, Q. C., Wudl, F., and Lucchini, V. (1993) Addition of Azides to Fullerene C60: Synthesis of Azafulleroids. J. Am. Chem. Soc. 115, 1148-1150.

(22) Cases, M., Duran, M., Mestres, J., Martin, N., and Solà, M. (2001) Mechanism of the Addition Reaction of Alkyl Azides to [60]Fullerene and the Subsequent $\mathrm{N}_{2}$ Extrusion to Form Monoimino[60]fullerenes. J. Org. Chem. 66, 433-442.

(23) Nierengarten, I., and Nierengarten, J.-F. (2014) Fullerene Sugar Balls: A New Class of Biologically Active Fullerene Derivatives. Chem. - Asian J. 9, 1436-1444.

(24) Yan, W., Seifermann, S. M., Pierrat, P., and Bräse, S. (2015) Synthesis of Highly Functionalized $\mathrm{C}_{60}$ Fullerene Derivatives and Their Applications in Material and Life Sciences. Org. Biomol. Chem. $13,25-54$.

(25) Kiviniemi, A., Mäkelä, J., Mäkilä, J., Saanijoki, T., Liljenbäck, H., Poijärvi-Virta, P., Lönnberg, H., Laitala-Leinonen, T., Roivainen, A., and Virta, P. (2012) Solid-Supported NOTA and DOTA Chelators Useful for the Synthesis of $3^{\prime}$-Radiometalated Oligonucleotides. Bioconjugate Chem. 23, 1981-1988.

(26) Österlund, T., Aho, A., Äärelä, A., Tähtinen, V., Korhonen, H., and Virta, P. (2020) Immobilized Carbohydrates for Preparation of 3'-Glycoconjugated Oligonucleotides. Curr. Protoc. Nucleic Acid Chem., DOI: 10.1002/cpnc.122.

(27) Luna Velez, M. V., Verhaegh, G. W., Smit, F., Sedelaar, J. P. M., and Schalken, J. A. (2019) Suppression of Prostate Tumor Cell Survival by Antisense Oligonucleotide-Mediated Inhibition of AR-V7 mRNA Synthesis. Oncogene 38, 3696-3709.

(28) An, F., Gong, B., Wang, H., Yu, D., Zhao, G., Lin, L., Tang, W., Yu, H., Bao, S., and Xie, Q. (2012) miR-15b and miR-16 Regulate TNF Mediated Hepatocyte Apoptosis via BCL2 in Acute Liver Failure. Apoptosis 17, 702-716.

(29) Guo, C. J., Pan, Q., Li, D. G., Sun, H., and Liu, B. W. J. (2009) miR-15b and miR-16 are Implicated in Activation of the Rat Hepatic Stellate Cell: An Essential Role for. J. Hepatol. 50, 766-778.

(30) Mäkilä, J., Jadhav, S., Kiviniemi, A., Käkelä, H., Liljenbäck, H., Poijärvi-Virta, P., Laitala-Leinonen, T., Lönnberg, H., Roivainen, A., and Virta, P. (2014) Synthesis of Multi-Galactose-Conjugated 2'-OMethyl Oligoribonucleotides and Their in vivo Imaging with Positron Emission Tomography. Bioorg. Med. Chem. 22, 6806-6813.

(31) Jadhav, S., Käkelä, M., Mäkilä, J., Kiugel, M., Liljenbäck, H., Virta, J., Poijärvi-Virta, P., Laitala-Leinonen, T., Kytö, V., Jalkanen, S., et al. (2016) Synthesis and In Vivo PET Imaging of Hyaluronan Conjugates of Oligonucleotides. Bioconjugate Chem. 27, 391-403.

(32) Makila, J., Kiviniemi, A., Saanijoki, T., Liljenback, H., Kakela, M., Jadhav, S., Poijarvi-Virta, P., Lonnberg, H., Laitala-Leinonen, T., Virta, P., Roivainen, A., et al. (2019) Noninvasive and Quantitative Monitoring of the Distributions and Kinetics of MicroRNA-Targeting Molecules in Vivo by Positron Emission Tomography. Mol. Pharmaceutics 16, 1507-1515.

(33) Astakhova, I. K., Santhosh Kumar, T., Campbell, M. A., Ustinov, A. V., Korshun, V. A., and Wengel, J. (2013) Branched DNA Nanostructures Efficiently Stabilised and Monitored by Novel PyrenePerylene 2 '-Alpha-L-Amino-LNA FRET pairs. Chem. Commun. 49, $511-513$.

(34) Marth, G., Hartley, A. M., Reddington, S. C., Sargisson, L. L., Parcollet, M., Dunn, K. E., Jones, D. D. D., and Stulz, E. (2017) Precision Templated Bottom-Up Multiprotein Nanoassembly Through Defined Click Chemistry Linkage to DNA. ACS Nano 11, 5003-5010.

(35) Lou, C., Martos-Maldonado, M. C., Madsen, C. S., Thomsen, R. P., Midtgaard, S. R., Christensen, N. J., Kjems, J., Thulstrup, P. W., Wengel, J., and Jensen, K. J. (2016) Peptide-Oligonucleotide Conjugates as Nanoscale Building Blocks for Assembly of an Artificial Three-Helix Protein Mimic. Nat. Commun. 7, 12294.

(36) https://www.bio-ad.com/webroot/web/pdf/lsr/literature/ Bulletin_7277.pdf.

(37) Cutler, I. J., Zhang, K., Zheng, D., Auyeung, E., Prigodich, E., and Mirkin, C. A. (2011) Polyvalent Nucleic Acid Nanostructures. J. Am. Chem. Soc. 133, 9254-9257.

(38) Fong, L.-K., Wang, Z., Schatz, G. C., Luijten, E., and Mirkin, C. A. (2018) The Role of Structural Enthalpy in Spherical Nucleic Acid Hybridization. J. Am. Chem. Soc. 140, 6226-6230.

(39) Randeria, P. S., Jones, M. R., Kohlstedt, K. L., Banga, R. J., Olvera de la Cruz, M., Schatz, G. C., and Mirkin, C. A. (2015) What Controls the Hybridization Thermodynamics of Spherical Nucleic Acids? J. Am. Chem. Soc. 137, 3486-3489.

(40) Mushtaq, S., Yun, S.-J., and Jeon, J. (2019) Recent Advances in Bioorthogonal Click Chemistry for Efficient Synthesis of Radiotracers and Radiopharmaceuticals. Molecules 24, 3567.

(41) Keinänen, O., Fung, K., Pourat, J., Jallinoja, V., Vivier, D., Pillarsetty, K. N., Airaksinen, A., Lewis, J. S., Zeglis, B. M., and Sarparanta, M. (2017) Pretargeting of Internalizing Trastuzumab and Cetuximab with a ${ }^{18} \mathrm{~F}$-Tetrazine Tracer in Xenograft Models. EJNMMI Res. 7, 95. 